\title{
THE EFFECT OF THE POP-UP BOOK AKU DAN GIGIKU ON BLOOD PRESSURE IN CHILDREN AGED 4-6 YEARS
}

\author{
KUSUMA P ADRIANI ${ }^{1}$, MARGARETHA SUHARSINI ${ }^{2 *}$, EVA FAUZIAH ${ }^{2}$, MEUTIA D CITRAWUNI ${ }^{1}$
}

${ }^{1}$ Pediatric Dentistry Residency Program, Department of Pediatric Dentistry, Faculty of Dentistry, Universitas Indonesia, Jakarta, Indonesia. ${ }^{2}$ Department of Pediatric Dentistry, Faculty of Dentistry, Universitas Indonesia, Jakarta, Indonesia.

Email: margarethasuharsini@gmail.com

Received: 16 September 2017, Revised and Accepted: 3 October 2017

\begin{abstract}
Objective: This study aimed to evaluate the effectiveness of the pop-up book Aku dan gigiku as an intervention strategy in reducing anxiety in young children before dental treatment.

Methods: 78 children aged 4-6 years were randomly divided into two groups: An intervention group with the pop-up book intervention and a control group without the pop-up book intervention. They were placed in a waiting room, and their blood pressure was measured. The experimental design of this clinical research was statistically analyzed using independent t-tests to compare decreased blood pressure between the intervention and control groups.
\end{abstract}

Results: The result of the study revealed that there was a statistically significant difference in decreased blood pressure with the intervention of the pop-up book Aku dan gigiku. As dental anxiety leads to undesirable distresses, it generates physiological changes such as blood pressure. Interventions should thus be undertaken to reduce dentalanxiety, and the pop-up book is an example of an intervention medium as it educates children and presents interesting illustrations.

Conclusion: The pop-up book Aku dan gigiku thus appears to be an effective method in reducing anxiety in children aged 4-6 years when used as an intervention strategy before dental treatment.

Keywords: Blood pressure, Children, Anxiety.

(c) 2017 The Authors. Published by Innovare Academic Sciences Pvt Ltd. This is an open access article under the CC BY license (http://creativecommons. org/licenses/by/4.0/) DOI: http://dx.doi.org/10.22159/ijap.2017.v9s2.44

\section{INTRODUCTION}

Dental anxiety leads to undesirable distresses, such as avoidance of dental treatment, and tends to increase stress among caregivers, consequently affecting treatment quality [1]. Anxiety is an unpleasant inner emotional state characterized by uncertainty from the anticipation of a threatening event or situation [2]. It is an emotional state that proceeds an encounter with a feared object or situation. This can involve physiological, cognitive, emotional, and behavioral components, although their expression may vary from one person to another [3]. Dental anxiety is described as a state of anxiety as it is brought on by dental treatment procedures and is related to negative expectations that are often linked to earlier traumatic experiences, negative family attitudes, fear of pain and trauma, and the perception of an unsuccessful and/or painful previous dental treatment [4]. Emotional factors such as anxiety can produce several physiological responses, for instance, in relation to blood pressure, heart rate, cellular metabolism, and mental activity [5].

Physiological responses to anxiety are the result of interactions between the environment and the information processed by the central nervous system. The body will trigger a psychophysiological process, such as sweating or breathing difficulties, through the activation of the hypothalamus-pituitary-adrenal axis and the sympathetic nervous system. The body produces mediators that are responsible for responding to stress, including the corticotropin-releasing hormone, the adrenocorticotropic hormone, glucocorticoids, and catecholamines. These mediators promote an increase in heart rate, blood pressure, cellular metabolism, and mental activity and are aimed at a homeostatic adaptation of the body in the face of a stressing agent, such as dental anxiety [6].

Many treatments have been found to be effective in decreasing anxious and disruptive behavior. These consist of interventions that often include modeling, relaxation, deep breathing exercises, distraction, and calming self-talk. A variety of behavioral interventions have been designed to reduce anxiety in children caused by dental procedures, such as the provision of information, live and filmed modeling, reinforcement of appropriate behavior, desensitization, tell-show-do, and many more [7]. The use of psychobehavioral approaches in medical and dental treatment situations is defined as a non-aversive approach aimed at modifying a child's discomfort by averting his or her attention away from the main task to accomplish successful treatment [1]. Intervention includes the provision of information; thus, giving information as a means of dental health education for children and doing so in a tell-show-do manner is likely to be more interesting for children. This information can be imparted through many tools, one of which is by means of a book. Studies have shown that the use of books with interesting and fun illustrations in promoting health education is generally well received by children [8].

There are many types of books, one of which is the pop-up book, which is of particular interest to this study. The pop-up book is a form of interactive literature that provides three-dimensional illustrations of cleverly folded paper that allows the pictures to appear real, whereby the child feels as if the books were coming alive [9]. The objective of this study was to evaluate the effectiveness of the pop-up book Aku dan gigiku as a predental treatment intervention in reducing anxiety in children aged 4-6 years.

\section{METHODS}

A total of 78 children of both sexes in the age group of 4-6 years were selected from five kindergartens in Jakarta. These children had no previous exposure to any dental treatment; there was an absence of pain of a dental origin, an absence of chronic illness, and no use of medication. Children with special needs were excluded from the study. The selected children's parents were informed of all the study details, and their written consent was required for their child's participation. This experimental clinical research design was carried out during August-September 2016. 
The children were randomly divided into two groups, one receiving either the pop-up book intervention or no intervention at all, thus an intervention group and a control group. Children from both groups were placed in a waiting room, and their blood pressure was measured using a pediatric automatic wrist sphygmomanometer. Each measurement was taken 3 times. After the first measurement, the children were randomly divided into two groups, one being the intervention group with the pop-up book Aku dan gigiku and the other being the control group. Each child in the intervention group was called in one-by-one to another room where the pop-up book Aku dan gigiku was read to them while being seated at the dental procedure station. During this time, they observed a variety of dental instruments. Thereafter, a second blood pressure measurement was taken before the oral prophylaxis procedure was performed. The blood pressure of the control group was measured immediately before the oral prophylaxis procedure, without the intervention of the pop-up book Aku dan gigiku, and the children were also seated at the dental procedure station while observing the dental instruments. The data were statistically analyzed using independent $\mathrm{t}$-tests, and the statistical significance was set at $\mathrm{p}<0.05$.

\section{RESULTS}

Before undertaking the statistical analysis, the Shapiro-Wilk test was applied to evaluate data normality. The data were analyzed by means of independent $\mathrm{t}$-tests for comparisons with or without the intervention, with the aim of evaluating the effectiveness of the pop-up book Aku dan gigiku as an intervention in reducing anxiety in children aged 4-6 years. The intervention group with the pop-up book Aku dan gigiku recorded a statistically significant difference in their systolic and diastolic blood pressure in comparison to the control group, which did not undergo the pop-up bookintervention.

The changes in systolic blood pressure presented in Table 1 summarize a significant difference in blood pressure between the intervention group and the control group, with $p=0.001(p<0.05)$. The same result for diastolic blood pressure changes is revealed in Table2.

\section{DISCUSSION}

Several studies have suggested that dental procedures might induce patient stress, thus generating anxiety and affecting the cardiovascular system. This anxiety can produce an increase in blood pressure in adults and children [1].

The present study showed that intervention using the pop-up book Aku dan gigiku seemed to be effective in reducing anxiety in relation to dental treatment and in assuring cooperative behavior in children who are about to undergo dental procedures. Both systolic and diastolic blood pressure changes showed a significant difference between the intervention group and the control group. Table 1 summarizes that the mean systolic blood pressure changes from the intervention group $(-14.08)$ and the control group (13.79), while Table 2 summarizes the

Table 1: Systolic blood pressure changes between the intervention and control groups

\begin{tabular}{llll}
\hline Group & $\mathbf{n}$ & Mean \pm SD $(\mathbf{m m H g})$ & $\mathbf{p}$ \\
\hline Intervention & 39 & $-14.08 \pm 8.405$ & 0.001 \\
Control & 39 & $13.79 \pm 12.092$ & \\
\hline
\end{tabular}

SD: Standard deviation

Table 2: Diastolic blood pressure changes between the intervention group and control groups

\begin{tabular}{llll}
\hline Group & $\mathbf{n}$ & Mean \pm SD $(\mathbf{m m H g})$ & $\mathbf{p}$ \\
\hline Intervention & 39 & $-5.79 \pm 10.746$ & 0.001 \\
Control & 39 & $4.62 \pm 3.109$ & \\
\hline
\end{tabular}

SD: Standard deviation diastolic blood pressure changes from the intervention group (-5.79) and the control group (4.62).

In anxiety-provoking situations, catecholamine release may increase both cardiac output and total peripheral vascular resistance by increasing the force of contraction of the heart and the excitability of the heart muscle. This pressure is mainly systolic blood pressure, and it is also responsible for a significant correlation between the rise in pulse rate and blood pressure [10]. Previous studies show that systolic blood pressure was significant before and after dental procedures, whereas diastolic pressure presented no significant difference [6]. In comparisons between the intervention and control groups, the changes in the systolic and diastolic blood pressure were significant $(\mathrm{p}<0.05)$.

An earlier study noted that psychobehavioral approaches can reduce anxiety, such providing each child with information about dental health education [7]. In this study, the pop-up book Aku dan gigiku served as the medium of intervention. This entailed the provision of information about dental health and dental health procedures in the form of a pop-up book. Pop-up books are particularly interesting and interactive for young children, as its unique pictures are unfolded in a way that appears to pop out of the book [9]. Each child became excited and very enthusiastic about the information is given while learning about dental health and dental procedures. They also got to see, touch, and re-enact the dental procedures, hence obtaining information in a tell-show-do approach. The tell-show-do approach is one way of reducing uncertainty and increasing predictability. It involves an explanation of what is about to happen, what instrument will be used and the reason, followed by a demonstration of the procedure, which the child can also carry out him/herself [3]. Our result shows the efficaciousness of the pop-up book Aku dan gigiku in reducing anxiety in young children.

\section{CONCLUSION}

Interventions using the pop-up book Aku dan gigiku appear to be effective in reducing anxiety in young children undergoing dental treatment. The study did not only report less anxiety before the dental treatment; it also shows a more positive response during the dental treatment. This study is important in the context of behavioral management in young children who experience anxiety while undergoing dental treatment. Given the strong association between anxiety and dental visiting, managing patients (in this case, pediatric dental patient) will go some way toward helping them improve their oral health. An interesting line of further research would be to look at special needs patients, children of different age groups, as well as the use of other intervention media.

\section{ACKNOWLEDGMENT}

This article was fully supported and financed by PITTA grant Universitas Indonesia.

The publication of this manuscript is supported by Universitas Indonesia.

\section{REFERENCES}

1. Al-Khotani A, Bello LA, Christidis N. Effects of audiovisual distraction on children's behaviour during dental treatment: A randomized controlled clinical trial. Acta Odontol Scand 2016:74:494-501.

2. McKay KA, Buen JE, Bohan KJ, Maye JP. Determining the relationship of acute stress, anxiety, and salivary alpha-amylase level with performance of student nurse anesthetists during human-based anesthesia simulator training. AANA J 2010;78:301-9.

3. Armfield JM, Heaton LJ. Management of fear and anxiety in the dental clinic: A review. Aust Dent J 2013;58:390-407.

4. Viswanath D, Kumar M, Prabhuji P. Dental anxiety, fear and phobia in children. Int J Dent Res Dev 2014;4:1-14.

5. Samra-Quintero PA, Bernardoni-Socorro C, Borjas AM, Fuenmayor NR, Estévez J, Arteaga-Vizcaíno M, et al. Changes in blood 
pressure in children undergoing psychological treatment before dental procedures. Acta Odontol Latinoam 2006;19:9-12.

6. Rodrigues Gomes SS, Barretobezerra AC, Maia Prado AC. Salivary biomarkers, vital signs and behaviour of pre-school children during their first dental visit. Eur J Paediatr Dent 2013;14:279-83.

7. Stark LJ, Allen KD, Hurst M, Nash DA, Rigney B, Stokes TF, et al. Distraction: Its utilization and efficacy with children undergoing dental treatment. J Appl Behav Anal 1989;22:297-307.

8. Aryani D. Buku Cerita Bergambar Sebagai Media Promosi
Kesehatan untuk Prevensi Dini Kekerasan Seksual pada Siswa SD di Kota. Yogyakarta: Fakultas Kedokteran Universitas Gajah Mada; 2009.

9. Paramastri I, Prawitasari JE, Prabandari YS, Ekowarni E. Booklet as a preventive media of child sexual abuse. J Kesehatan Masyarakat Nasional 2011;6:77-84.

10. Versloot J, Veerkamp J, Hoogstraten J. Dental anxiety and psychological functioning in children: Its relationship with behaviour during treatment. EurArch Paediatr Dent 2008;9 Suppl 1:36-40. 